\title{
A COMPARATIVE TRIAL BETWEEN DICLOFENAC-GENTAMICIN AND BETAMETHASONE-NEOMYCIN DROPS IN PATIENTS UNDERGOING CATARACT EXTRACTION
}

\author{
J. SUHARWARDY ${ }^{1}$, C. LING ${ }^{2}$, J. A. BELL ${ }^{3}$ and C. G. F. MUNTON ${ }^{4}$ \\ Maidstone
}

\begin{abstract}
SUMMARY
Eighty patients were randomised in a single-masked parallel-group study to receive topically either the test drug, a diclofenac and gentamicin combination, or a betamethasone and neomycin combination after routine cataract extraction and intraocular lens implantation. Each group was assessed over a 6 week period for postoperative inflammation. The two drug combinations were equally effective in suppressing inflammation in the early post-operative stages and the diclofenac-gentamicin combination was slightly more effective in the later stages. The test drug was well tolerated and showed no adverse effects. We feel it is an effective and relatively safe drug which has a role as an anti-inflammatory agent after cataract extraction and has potential advantages in certain circumstances.
\end{abstract}

It is standard ophthalmic practice to treat patients who have had a cataract extraction with a post-operative course of a topical steroid and antibiotic. ${ }^{1.2}$ The potential sideeffects of steroid are well known and there is interest in ophthalmology in the use of non-steroidal anti-inflammatories. ${ }^{2.3}$ The object of this study was to compare the safety and efficacy of the trial drug, a diclofenac-gentamicin combination, with betamethasone-neomycin drops.

Diclofenac sodium has been used as a systemic antiinflammatory for many years and studies have shown an anti-inflammatory effect on the eye following systemic administration. ${ }^{3}$ Other non-steroidal anti-inflammatories have been used in topical form in the management of cystoid macular oedema and in the prevention of perioperative miosis during cataract extraction. ${ }^{2-4}$ American

From: 'The Oxford Eye Hospital, Oxford; 'Princess Alexandra Eye Pavilion, Edinburgh; ${ }^{3}$ Kent and Sussex Hospital, Tunbridge Wells, Kent; ${ }^{4}$ Kent County Ophthalmic Hospital, Maidstone, UK.

Correspondence to: Mr J. Suharwardy, The Oxford Eye Hospital, Walton Street, Oxford OX2 6AN, UK. studies have shown the effectiveness of cyclo-oxygenase inhibitors after cataract extraction. ${ }^{56}$ We report on our experience of topical diclofenac, in combination with gentamicin, as an anti-inflammatory agent in the post-operative management of cataract surgery.

\section{MATERIALS AND METHODS}

This was a randomised single-masked (investigator masked) parallel-group comparison of $0.1 \%$ diclofenac sodium $/ 0.3 \%$ gentamicin preserved with $0.01 \%$ benzoxonium chloride (DR 1352/1, Ciba Vision) and $0.1 \%$ betamethasone sodium phosphate $/ 0.5 \%$ neomycin sulphate preserved with thiomersal $0.004 \%$ (Betnesol-N). The anti-inflammatory/antibiotic combination was used for 2 weeks (stage 1) and then the antibiotic was stopped. Thereafter one group continued solely on diclofenac sodium whilst the other continued with betamethasone sodium (stage 2). Treatment was used 4 times a day; it began 1 day before surgery and was continued up to the visit at days $41-43$.

Eighty patients were enrolled on the study, selected after satisfying the exclusion criterion and giving informed consent as agreed with the hospital ethics committee. The patients were between 30 and 84 years of age and undergoing extracapsular cataract surgery with intraocular lens (IOL) implantation. Patients with any ocular malformation were excluded, as were patients with a history of previous intraocular inflammation or glaucoma. Other exclusion criteria included: chronic or acute conjunctivitis or keratitis, dry eye syndrome, contact lens wear, ocular surgery within the previous 2 months, treatment with either local or systemic anti-inflammatories or antibiotics within the previous 14 days, and known steroid response.

Patients were randomly assigned to one of two groups and assessed pre-operatively on admission (examination 
Table I. Scoring system used in the assessment of the six key primary symptoms and signs of inflammation

\begin{tabular}{|c|c|c|c|c|}
\hline & $\begin{array}{c}\text { None } \\
0\end{array}$ & $\underset{1}{\text { Light }}$ & $\begin{array}{l}\text { Moderate } \\
\quad 2\end{array}$ & $\begin{array}{l}\text { Severe } \\
3\end{array}$ \\
\hline Burning/itching & Not present & Not disturbing & Disturbing & Painful \\
\hline Ocular pain & Not present & Not disturbing & Moderate & Tormenting \\
\hline $\begin{array}{l}\text { Conjunctival hyperaemia } \\
\text { Corneal oedema }\end{array}$ & None & $\begin{array}{l}\text {-According to a } \\
\text { Epithelial }\end{array}$ & Epithelial and stromal & $\begin{array}{l}\text { Epithelial and stromal with } \\
\text { Descemet's folds }\end{array}$ \\
\hline $\begin{array}{l}\text { AC flare } \\
\text { AC cells }\end{array}$ & $\overleftarrow{\text { None }}$ & \multicolumn{2}{|c|}{$\begin{array}{l}\text {-According to a standard chart- } \\
1-10^{a}\end{array}$} & exp \\
\hline
\end{tabular}

AC, anterior chamber.

a Per $3 \mathrm{~mm}^{2}$ field.

I). After surgery they were seen on six occasions by the same four doctors on the following days: day 1, days 3-6, days 12-16, days 21-24, days 27-29 and days 41-43 (examinations II to VII].

The surgery was performed by two named surgeons (C.G.F.M. and J.A.B.) to an agreed protocol regarding technique and materials. A routine extracapsular cataract extraction was done with a limbal incision, a 'can-opener' capsulotomy under hydroxypropylmethylcellulose (HPMC), manual expression of the nucleus, manual aspiration and irrigation of soft lens matter and IOL implantation under HPMC. The section was sutured with 8.0 vicryl and a subconjunctival injection of cefuroxime was given. The viscoelastic was not routinely removed at the end of surgery.

Drug efficacy was assessed by observing the effect of the drug on the primary and secondary symptoms and signs of inflammation.

The six key primary symptoms and signs of inflammation were defined as: (1) burning/itching, (2) ocular pain, (3) corneal oedema, (4) conjunctival hyperaemia, (5) anterior chamber flare, (6) anterior chamber cellular activity. Each patient was seen by one of four doctors (J.S., C.L., J.A.B., C.G.F.M.) on each visit; in an attempt to standardise the results the symptoms and signs were given a score from 0 to 3 based on the severity of the findings as classified in Table I.

Instruments such as the Kowa laser flare and cell meter have recently been developed and allow a more objective measurement of anterior chamber activity. ${ }^{7.8}$ It was felt, however, that differences between the two topical preparations detectable only with the flare and cell meter would not be clinically significant. The method of clinical assessment used was therefore based on that described by Hogan and co-workers. ${ }^{9}$ The cellular activity was determined from the number of cells seen in a standard oblique slit beam ( $3 \mathrm{~mm}$ long and $1 \mathrm{~mm}$ wide) whilst the flare was assessed by comparing the density of the flare with that showed on a graded standard chart.

The secondary signs were defined as ciliary hyperaemia, conjunctival discharge and the presence of iris synechiae (in the undilated resting state); they were also assessed on each examination. They were judged to be either absent or present and given a score of 0 or 2 accordingly.

Tolerance to the treatment was also assessed on each visit. Both burning/itching and hypersensitivity after installation of the drops were assessed and judged to be either not present, present but not disturbing, disturbing, or painful. In addition both doctor and patient rated the overall local tolerance of the drops, and also the success of the therapy, as either excellent, good, fair or poor. A score of $0,1,2$ or 3 was given on each occasion.

The results were analysed by two tests of independence in a two-way table, namely chi-squared with Yates' correction and Fisher's exact test. The sum of the scores for both key and secondary signs and symptoms was determined for the patients on each visit allowing a mean score for each group on each examination to be calculated. Subsequent statistical analysis involved two-group $t$-tests and analysis of variance, using Bonferroni's criterion for assessing the statistical significance of multiple comparisons between means. ${ }^{10.11}$

\section{RESULTS}

Eighty patients were enrolled on the study of whom 2 were excluded from the safety analysis due to violation of the exclusion criteria. Seventy-eight patients were therefore assessed for drug safety and tolerance. Eight patients were excluded during stage 1 of the trial; 4 of these were excluded due to peri-operative changes in the surgical protocol, 1 patient died due to a cerebrovascular accident post-operatively, 2 were lost to follow-up and 1 was discovered to have suffered from chronic simple glaucoma. A further 3 patients were excluded from stage 2 of the trial; 2 were lost to follow-up and 1 in the Betnesol-N group Mean Score

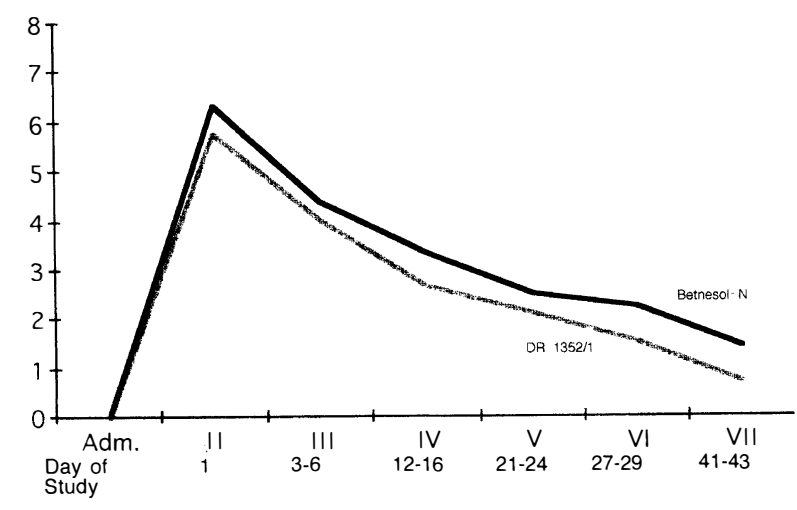

Fig. 1. Mean inflammatory score for primary criteria of inflammation versus day of study. Adm., admission. 
Table II. Mean inflammatory scores against day of study for primary inflammatory signs/symptoms

\begin{tabular}{llllllll}
\hline & \multicolumn{8}{c}{ Day of study } \\
\cline { 2 - 8 } & Adm. & 1 & $3-6$ & $12-16$ & $21-24$ & $27-29 *$ & $41-43 *$ \\
\hline DR 1352/1 & 0 & 5.8 & 4.03 & 2.7 & 2.13 & 1.57 & 0.7 \\
Betnesol-N & 0.06 & 6.36 & 4.39 & 3.3 .3 & 2.52 & 2.27 & 1.42 \\
\hline
\end{tabular}

Adm., admission.

* Indicates a difference between the scores where $p<0.05$.

developed an adverse drug reaction at the end of stage 1 of the trial. Sixty-seven patients were therefore assessed for drug efficacy.

Of the 78 patients assessed for tolerance 38 received the test drug diclofenac-gentamicin and 40 received Betnesol-N. There were 34 men and 44 women with a mean age of 72.6 years and a range of 46-84 years. Fifty-nine operations were performed with the patient under local anaesthetic, 19 under general anaesthetic.

The mean scores of the primary key symptoms and signs of inflammation are shown plotted against time in Fig. 1 and are listed in Table II. Overall the mean inflammatory scores for the two groups were similar. In the later part of the trial there was a small difference between the two scores with a slightly lower score for the test drug $(p<0.05)$. When each sign or symptom was considered separately there was generally little difference between the two groups. There was, however, a slightly lower degree of anterior chamber cellular activity from examinations IV to VII and anterior chamber flare activity on examinations IV and VII in the diclofenac group (chisquared test, $p<0.05)$.

Analysis of the secondary signs of inflammation (iris synechiae, discharge and ciliary hyperaemia) showed a significantly lower score in the Betnesol-N group immediately post-operatively, but a lower score for the test drug on examinations VI and VII $(p<0.05)$. The mean scores are shown plotted in Fig. 2 and in Table III. On all of these occasions ciliary hyperaemia was the only reason for the difference. Conjunctival discharge and iris synechiae occurred rarely and showed no difference between the groups.

MEAN SCORE

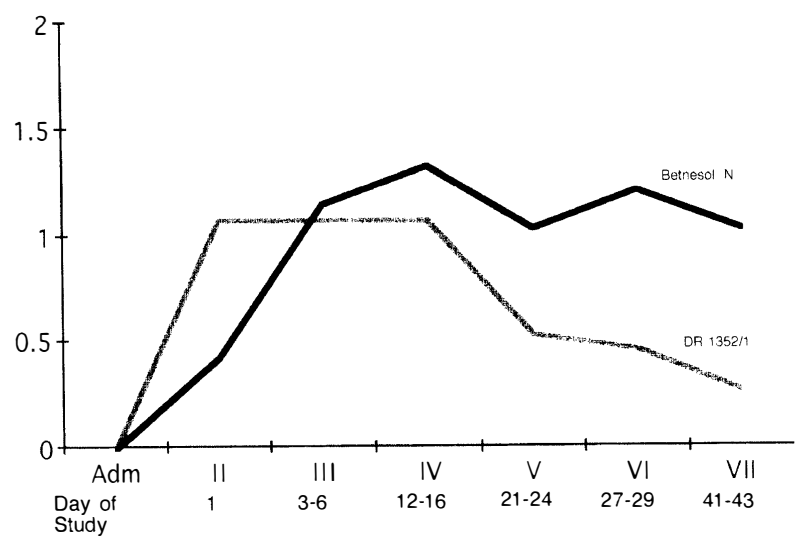

Fig. 2. Mean inflammatory score for secondary criteria of inflammation versus day of study: Adm., admission.
The results for local tolerance showed that during the study there was a steady decrease, similar in both groups, in the number of patients complaining of burning or itching after application of the drops.

There was also no difference in the overall tolerance of the therapy as assessed by both doctors and patients in the initial part of the study. On the examinations VI and VII, however, there was a better tolerance to the test drug as reflected by the number of patients and doctors rating the test drug as excellent compared with good or fair for the betamethasone-containing drop $(p<0.05)$. Analysis of the 'success of therapy' results as judged by both doctors and patients showed a similar trend.

The median intraocular pressure in both groups remained between 12 and $16 \mathrm{mmHg}$ during the course of the study. Two cases in the diclofenac group showed a transient post-operative spiking of pressure above 25 $\mathrm{mmHg}$.

There was 1 case of adverse drug effect clinically felt to be neomycin allergy and there were no problems in the non-operated fellow eyes assessed during the study.

\section{DISCUSSION}

The mechanism of action of diclofenac and other nonsteroidal anti-inflammatories is by the inhibition of the enzyme cyclo-oxygenase at the core of prostaglandin metabolism. The release of cell membrane phospholipids from damaged cells and the subsequent action of the enzyme phospholipase A produces free arachidonic acid. This acts as a substrate for either lipoxygenase with the subsequent production of leukotrienes or as a substrate for cyclo-oxygenase to produce the endoperoxide $\mathrm{PGG}_{2}$, which is a precursor of the prostaglandins, prostacyclins and thromboxanes. ${ }^{2}$ The role of these mediators of inflammation is still being defined, but specific ocular effects have been identified. The problems of intra-operative miosis, post-operative inflammation with breakdown of the blood-aqueous barrier (as assessed by anterior segment ocular fluorophotometry) and the development of cystoid macular oedema are related in part, to the action of prostaglandin.

By inhibiting cyclo-oxygenase the synthesis of these mediators of inflammation is inhibited. However, it is also possible that by this selective inhibition and subsequent build-up of arachidonic acid there might be an increase in the lipoxygenase pathway with an increase in formation of the chemotactic leukotrienes. One laboratory has suggested that this could have the potential for the enhance- 
Table III. Mean inflammatory scores against day of study for secondary inflammatory signs/symptoms

\begin{tabular}{llllllll}
\hline & \multicolumn{8}{c}{ Day of study } \\
\cline { 2 - 8 } & Adm. & $1^{*}$ & $3-6$ & $12-16$ & $21-24$ & $27-29 *$ & $41-43^{*}$ \\
\hline DR 1352/1 & 0 & 1.07 & 1.07 & 1.07 & 0.53 & 0.47 & 0.27 \\
Betnesol-N & 0 & 0.42 & 1.15 & 1.33 & 1.03 & 1.21 & 1.03 \\
\hline
\end{tabular}

Adm., admission.

* Indicates a difference between the scores where $p<0.05$.

ment of a granulomatous process, although aggravation of ocular inflammation has not been reported as a clinical problem with cyclo-oxygenase inhibitors at present. ${ }^{3.21}$

Corticosteroids are effective inhibitors of phospholipase $\mathrm{A}$ and therefore of prostaglandin formation, but their actions extend beyond the prostaglandin pathway with effects on white cells, lysosomal enzyme release and fibroblastic activity. ${ }^{3}$ The ocular side-effects of topical steroids include inhibition of healing, elevation of intraocular pressure and increased risk of infection, and are well documented. ${ }^{13-15}$

Cyclo-oxygenase inhibitors (COI) have been used topically on the eye for some years. Anterior segment ocular fluorophotometry was used in identifying the role of COI in the inhibition of the breakdown of the blood-aqueous barrier and experience has been gained with the use of $\mathrm{COI}$ in the inhibition of peri-operative miosis and the management of post-operative cystoid macular oedema. ${ }^{16-20}$

The degree of inflammation seen after cataract surgery can be variable and the technique of cataract surgery performed influences this. The use of phacoemulsification through small scleral tunnels with or without a sutured section has increased over recent years. It allows quicker visual rehabilitation and also a shorter post-operative course of topical anti-inflammatory therapy. In routine cases a steroid and antibiotic are used for 3 weeks, followed by only steroid drops for 1 week, giving a total course of treatment of 28 days. ${ }^{22}$ It is on this changing face of cataract surgery that anti-inflammatory agents will be assessed in future clinical practice.

In this trial diclofenac was effective in the control of inflammation after routine extracapsular cataract surgery. It appeared to be at least as effective as steroid therapy in the early post-operative stages and at 4-6 weeks postoperatively may even have some advantages on anterior chamber activity. It appeared to be a safe drug and was tolerated well. There were no cases of adverse drug effects and there was a favourable assessment by both doctors and patients for the drug.

This study suggests that diclofenac sodium-gentamicin appears to be an acceptable alternative to conventional steroid/antibiotic preparations after catataract surgery. Whilst the general trend recently has been towards shorter post-operative courses of anti-inflammatories we feel that diclofenac sodium is a useful addition as another antiinflammatory agent and has a particular use in patients with a previous history of recurrent herpetic infection or steroid-responsive glaucoma.
The authors acknowledge the funding for the trial by CIBA Vision. None of the four authors has a commercial or financial interest in the drug diclofenac-gentamicin.

Key words: Anti-inflammatory, Cataract surgery, Diclofenac sodium.

\section{REFERENCES}

1. Starr MB. Prophylactic antibiotics for ophthalmic surgery. Surv Ophthalmol 1983;27:353-73.

2. Caronia RM, Obstbaum SA. Drug therapy before, during and after cataract surgery. Curr Opin Ophthalmol 1993;4: 61-74.

3. Flach AJ. Cyclo-oxygenase inhibitors in opthalmology. Surv Ophthalmol 1992;36:259-84.

4. Connor TB, Pulido JS. Management of aphakic and pseudophakic cystoid macular edema. Cur Opin Ophthalmol 1993; 4:90-101.

5. Kraff M, Sanders D, McGuigan L, Raanan M. Inhibition of blood-aqueous humor barrier breakdown with diclofenac. Arch Ophthalmol 1990;108:380-3.

6. Vickers F, McGuigan L, Ford C, Wysowskyj H, Mellars K, Koester J, Ahmed M. The effect of diclofenac sodium ophthalmic on the treatment of postoperative inflammation. Invest Ophthalmol Vis Sci 1991;15:69-73.

7. Shah SM, Spalton DJ, Smith SE. Measurement of aqueous cells and flare in normal eyes. Br J Ophthalmol 1991;75: 348-52.

8. Shah SM, Spalton DJ. Changes in anterior chamber flare and cells following cataract surgery. Br J Ophthalmol 1994;78: 91-4.

9. Tessler HH. Classification and symptoms and signs of uveitis. In: Tasman W, Jaeger EA, editors. Duane's clinical ophthalmology, vol 4. Philadelphia: JB Lippincott, 1989.

10. Siegel S. Nonparametric statistics for the behavioral sciences. New York: McGraw-Hill, 1956.

11. Fleiss JL. The design and analysis of clinical experiments. New York: Wiley, 1986.

12. Walter JB, Israel MS. General pathology, 6th ed. Edinburgh: Churchill Livingstone, 1987.

13. Masket S. Comparison of the effect of topical corticosteroids and non-steroidals on post-operative corneal astigmatism. J Cataract Refract Surg 1990;16:715-8.

14. Becker B, Mills D. Corticosteroids and intraocular pressure. Arch Ophthalmol 1963;70:500-7.

15. Kanski JJ. Clinical ophthalmology, 2nd ed. London: Butterworths, 1989.

16. Alpar JJ, McGuigan L, Alpar AJ. Effect of diclofenac sodium ophthalmic $0.1 \%$ on inflammation following cataract extraction: a fluorophotometry study [abstract]. Ophthalmology 1989;(Suppl) 96:109.

17. Heinrichs D, Leith A. Effect of flurbiprofen on the maintenance of pupillary dilatation during cataract surgery. Can $\mathrm{J}$ Ophthalmol 1990;25:239-42.

18. Drews R, Kastev D. Ocufen and pupillary dilation during cataract surgery. J Cataract Refract Surg 1989;15:445-9.

19. Flach AJ, Dolan BJ, Irvine AR. Effectiveness of ketorolac tromethamine $0.5 \%$ ophthalmic solution for chronic aphakic 
and psedophakic cystoid macular edema. Am J Ophthalmol 1987;103:479-86.

20. Flach AJ, Lampol LM, Weinberg D, Kraff MC, Yannuzzi LA, Campo RV, et al. Improvement in visual acuity in chronic aphakic and pseudophakic cystoid macular edema after treatment with topical $0.5 \%$ ketorolac tromethamine. Am J Ophthalmol 1991; 112:514-9.
21. Rao NA, Patchett R, Fernandez MA, et al. Treatment of experimental granulomatous uveitis by lipoxygenase and cyclo-oxygenase inhibitors. Arch Ophthalmol 1987;105: 413-5.

22. Fung WE, Phacoemulsification. In: Tasman W, Jaeger EA, editors. Duane's clinical ophthalmology, vol. 6 Philadelphia: JB Lippincott, 1993. 